\title{
Priorities of the logistics risks management in the resource support of construction projects
}

\author{
Tatiana Kubasova ${ }^{1, *}$, Vladimir Tkach $^{2}$, and Irina Tsvigun ${ }^{1}$ \\ ${ }^{1}$ Baikal State University, 664003, Lenin str., 11, Irkutsk, Russia \\ ${ }^{2}$ Saint Petersburg State University of Economics, 191023, Sadovaya str., 21, Saint Petersburg, Russia
}

\begin{abstract}
The article deals with the problem of the logistics risks management in the resource support of construction projects based on the complex accounting of modern approaches to the management of functional areas of logistics and supply chains. It is argued that these issues have not been provided with sufficient attention in the academic publications. The state of the construction industry is examined, and critical analysis is carried out. The distinctive features of risks associated with the provision of construction services, due to their intangible components are characterized. The institutional specifics of regulation in the sphere of construction services are disclosed, and the limits of management of logistics risks through the use of special software are justified. The priorities for managing such risks in the resource support of construction projects are set. The targeted nature of the international quality standards regulation for the management of the organization's risk on the basis of a systematic approach has been argued. The authors point out integration of the risk management in the management of sustainable development of enterprises as an independent functional unit. The necessity of differentiating the management of the design logistics risks in the resource support of construction, and the risk management in the operational logistics activities carried out in course of the implementation of construction projects is substantiated. The contract strategy of the resource support for construction projects, which determines the rules of coordination of the project conditions of supply contracts, logistic coordination of deliveries, procurement placement (including the rationale for the methods of such placement) and rapid response to negative logistics precedents is characterized in the paper. It is concluded that there is a need to coordinate supplies in the projects' resource support system, taking into account the specificity of the functional cycles of logistics and the applicability of alternative methods of intervening in the operational logistics activities.
\end{abstract}

Integration of risk management based on the complex approach to the overall management of the enterprise is one of the central requirements of the modern concept of a quality management system. The need for this step is extremely important for Russian organizations, since the economic recession generates uncertainty that creates serious obstacles to the achievement of corporate objectives. However, in Russia the tendency to incorporate risk management into the enterprise's activities to ensure the effectiveness of its business

\footnotetext{
*Corresponding author: lenina424@ yandex.ru
} 
operations and maintain the economic and financial balance is still far from being recognized as total. This statement extends, practically, to all sectors of economy, excluding the sphere of insurance, where risk management is the leading component of the organization of their service provision. In the latter context, it is necessary to emphasize the construction industry, the enterprises of which most often demonstrate underestimation of risk management in the implementation of their projects. Such a behavior is manifested, first of all, in housing construction, so the response of stakeholders very often becomes resonant. The state does not leave this issue unattended. In particular, the authorities take institutional measures to protect consumers of housing construction services. In this situation, construction organizations are forced to search for effective organizational and economic mechanisms for managing industry's risks that meet modern realities. The solution to this problem should be sought, first, in improving the quality of management of the project risks and operational activities in the process of implementing construction projects. In this field, works to find opportunities of reducing the values of logistics risks in the resource support of construction projects to the acceptable level should be considered as one of the priority directions. All this causes academic and practical interest to such studies.

In the most acute form, the issues of risks of the construction projects management are manifested in the construction of residential real estate on the principles of equity participation. In the Russian academic publications, they are considered in a quite comprehensive way. For example, [1,2] address the results of research of the factors, defining risks of consumers of services of this sector enterprises. In [3], the analysis of institutional rules for regulation of housing construction is carried out, based on the systemic principle, and projections are made with respect to the prospects for its development and the reduction of sectoral risks. Some other works [4] specifies peculiarities of the quality management services in the practice of Russian construction enterprises on the basis of international standards ISO. It is appropriate to remind here that mandatory formalization of the risk management policy by enterprises is one of their basic requirements. In [5], it is noted that the task of the project risk management is relevant, taking into account the logistic component of the resource support. However, the recommendations how to solve this problem are extremely generalized. The detailed analysis of these and other works devoted to the issues under consideration shows that the logistics aspects of such management in the field of resource support for the construction projects are not properly discussed. There different reasons for this phenomenon.

First, investment financing is the leading component of project management, the role of which in the situation of tight budget constraints is growing. The complexity of organization of this process and high administrative responsibility for this activity predetermine the redistribution of the main functions in managing construction projects in favor of financial management. Representatives of the latter often underestimate the contribution of logistics and supply chain management, including the management of logistics risks, to rationalizing the resource support of such projects. The incomplete understanding of the organizational and economic nature of the supply management and the need in special measures to guarantee its reliability is the most common mistake. Meanwhile, the importance of this issue in the context of strengthening the trend of a large-scale transition to the integrated development of territories is very much growing.

Secondly, the prevailing interest to the investment aspects of construction projects and changes in the governmental regulation of the industry is conditioned by its general state, which needed improvement for a long time. Therefore, we will address the changes taking place in the construction industry in more details.

According to official statistics, in 2017 compared with the previous year, the amount of commissioning of housing in Russia slightly decreased. This volume of housing commissioning was achieved mainly because of the progress in mortgage lending. At the 
same time, in 2017 no background appeared for the growth of business activity in the industry. In this year, more than $70 \%$ of the construction organizations assessed the situation in the industry as just satisfactory [6]. In general, most enterprises of the industry did not expect positive changes on the market of the construction services. Only $60 \%$ of them had loading of the production capacities exceeding the threshold level of the criterion for ensuring their economic security. It should be noted that earlier (in 2016) there was a trend towards economic recovery of the construction industry (Figure 1). However, this result was largely achieved due to the negative demographic situation in this service sector (Figure 2).

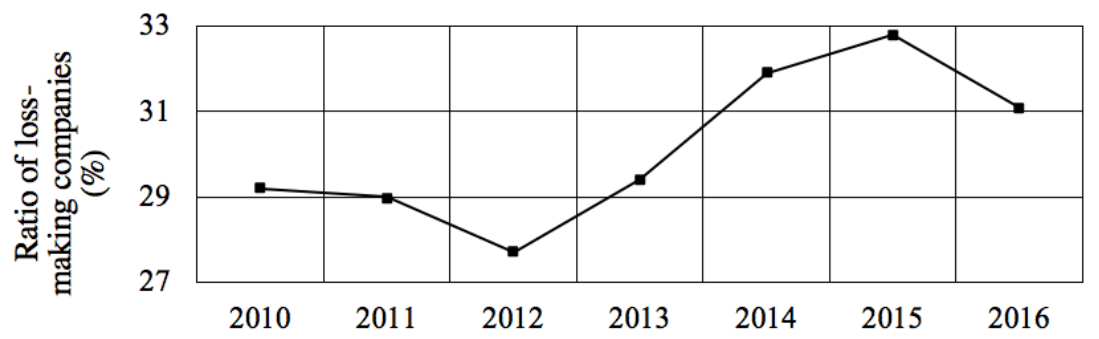

Fig. 1. Dynamics of changes in the number of loss-making construction organizations [6]

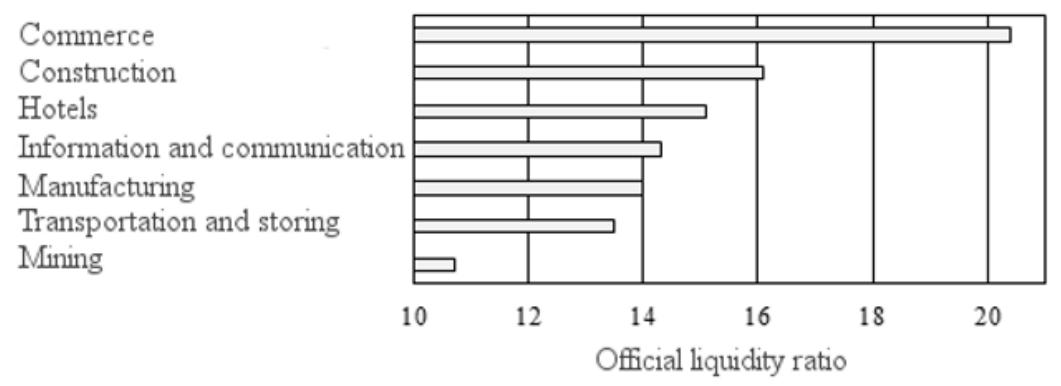

Fig. 2. Peculiarities of demography of the Russian construction organizations in 2017 [7].

In 2017, the steady development of the construction organizations, according to the Federal State Statistics Service of the Russian Federation, was hampered by traditional for the economic recession factors (Figure 3). First of all, it is necessary to point out among them negative for such enterprises changes in the structure of demand for their services. It should be noted that in accordance with the theory of Janos Kornai, in the period of tight budget constraints the consumers adapt to them in three invariant ways [8]. This pattern can be extended to the behavior of customers of the construction services, who in this situation: 1) reduce the volume of their consumption; 2) seek to switch to the consumption of cheaper services or postpone the placement of orders for their provision; 3) reduce the list of consumption of such services to a minimum.

The Federal State Statistics Service of the Russian Federation does not monitor contractual sectoral risks in the construction sector. However, a general idea about such risks can be drawn up on the basis of analysis of the dynamics of the number of cases in the arbitration courts related to the improper fulfillment of supply contracts (Figure 4). They testify, on the one hand, the growth of contractual risks, including logistics risks, and the insufficient scale of the resolution of business disputes through pre-trial settlement on the other hand, for example, made through commercial negotiations or mediation [10]. 


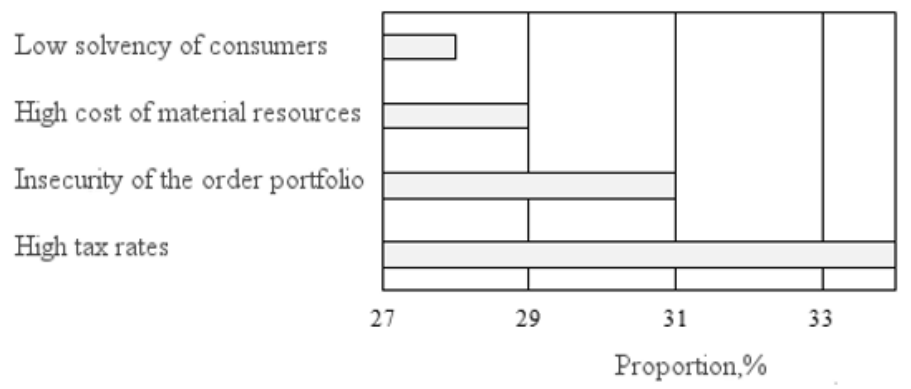

Fig. 3. Obstacles on the way of sustainable development of the construction organizations [6].

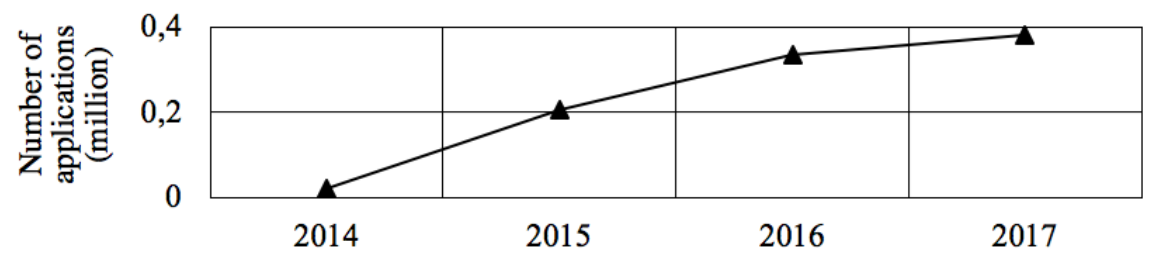

Fig. 4 Dynamics of changes in the number of applications to the arbitration courts in connection with improper fulfillment of contractual obligations by suppliers of material resources [9].

The state understands that the risks of consumers of services of this industry are unacceptably high, especially in the sphere of housing construction. It has already been noted that the state undertakes institutional measures to protect consumers, above all, of a legislative nature. However, the state does not limit its efforts to this, implementing, in particular, technical regulation in the sphere of construction services. It is advisable to particularly point out the standard [11], which sets out the requirements for the qualification tests of the construction organizations and evaluation of their reputation. Before describing it, it is necessary to note a number of provisions. First, although the construction service is characterized as material one, part of this service is intangible. To some extent, this feature objectively complicates the completeness of specification of the requirements for that service, which is already a risk factor by itself. Secondly, the construction service includes two types of activities. One of them is intra-firm (it consists of resource support for the construction projects and construction production). The second consists of the direct interaction of the contractor and the customer of the construction service (business contacts and servicing customer through a direct contact). Obviously, the first type of activity is not visible for the consumers of services (especially when the construction of real estate has not yet started). The quality and degree of risks of the resource support for the construction projects, the main component of which is material and technical supply, production and technological equipment, management of supply chains of material resources, etc. is not clear [12]. Construction organizations actively use this circumstance when developing a marketing strategy. In accordance with it, meetings with potential customers of services are often carried out on the basis of pre-scenarios, meaning that they use manipulative techniques.

The model of reputation assessment of the construction organization, which was formulated in [11], as a whole, allows obtaining a reliable expert estimation. Logistics risks of the resource support of construction projects are not directly taken into account in it. However, it is focused on determining the rhythm of construction works, which can be considered as one of the indicators of an indirect assessment of such risks. This model also considers failures in commissioning the facilities by the construction organizations that, in the first approximation, also characterizes the logistics risks. In addition, it intends assessing 
the quality of labor protection in the company. These results, too, indirectly form an idea about the logistics risks, since in course of the construction process, some loading and unloading operations are carried out, during which various emergency incidents cannot be excluded. It should be noted that transshipment of cargoes is traditionally associated with logistics risks. This circumstance, in particular, is taken into account in the main activity of the insurance companies, which establish tariffs for their services directly depending on the number of transshipments.

Certain opportunities to manage the logistics risks are associated with the use of the special software by organizations. Official statistics provide information on this practice without taking into account the sectoral affiliation of enterprises (Figure 5). However, this analysis still allows us drawing a number of conclusions. First, only a small part of the Russian enterprises use ERP, SCM and other software that include units for the risk management of different functionality. This situation is predetermined not only by the fact that their acquisition is associated with significant capital investments. Installment of such units requires both considerable staff efforts and new investments in the modernization of special software, which is simply beyond the possibilities of many enterprises in the situation of the economic recession. It should be noted that such information technologies offer rather simplistic solutions of logistics tasks and tasks of supply chain management. For example, the concept of RP-class systems does not provide for the formation of insurance stocks, and the optimization of supply chains is carried out by searching for a simple balance in the system <suppliers $\rightarrow$ target enterprise $\rightarrow$ consumers>. It means that they underestimate the transaction restrictions that have a significant impact on ensuring the reliability and sustainability of supply plans in the supply and marketing activities of enterprises [13, 14]. In addition, evaluating effectiveness of the RP-class systems and other similar software is a very difficult task. More simplified similar means, for example, domestic "1C" class system, allow taking into account only certain logistics risks, in particular, the risk of non-fulfillment of contractual obligations by contractors. However, this is a task of the limited nature, since the subject of verification is only the fact that the suppliers have legal capacity and authority. It is worth mentioning that the use of special software, regardless the breadth of its logistics functions and the scope of providing support for management decisions creates new risks, including logistics ones. They are caused by the likelihood of malfunctions in the process of software operation and unreasonable reliance of managers on the solutions offered by such information technologies. The latter problem is directly related to the question of the permissible possibility and limits of "transfer" of management responsibility to technical systems.

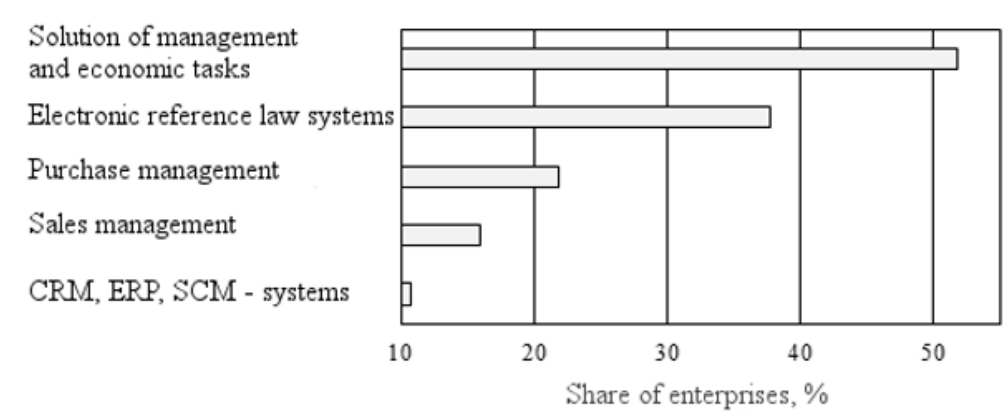

Fig. 5. Use of special software for managing the core business by the Russian enterprises in 2016 [7].

Priorities of managing the logistics risks in the resource support of construction projects should be determined, at least, taking into account the following factors. First, it is necessary to be guided by the recommendations on risk management provided in the international 
quality standards and the Russian national standards [15-17]. The latter, as our studies show, under the influence of the evolution of the ISO regulations, acquire a clear focus on both the organization's risk management on the basis of a systemic approach and its integration as an independent functional unit in managing sustainable development of enterprises [18]. The organization's exit to such a trajectory is made dependent on balancing its interactions with suppliers, consumers, society and the state, that is, with all stakeholders. The legality of such a position does not raise any doubts, since such relations have long received the status of a specific resource. To some extent, the acquisition of network characteristics by national economies facilitates this. Second, it is necessary to differentiate the management of the project logistics risks in resource support for construction, and the risk management in operational logistics activities performed in course of implementing construction projects. Both kinds of this management are theoretically based on a similar decision making design. However, in the framework of the first of them, special significance has a formal analysis of construction projects and an evaluation of the investment plan $[15,16,19]$. Their common task is to understand the possibility of ensuring the required project effectiveness, i.e. to justify the likelihood of achieving the project objectives. In the framework of its solution, it is necessary to establish not only logistics risks of the project, but also the peculiarities and economic consequences of their penetration into the operational logistics activities of the construction organization. In this context, the starting point is the justification of the scope of suppliers involved in the resource support of the projects under consideration, and a critical analysis of the prospects to build supply chains with them [20,21]. Modern requirements for their formation envisage ensuring not only reliability of supply, but also their safety and stability [22, 23]. It should be noted that the complexity of meeting these conditions is determined not only by statistical deviations in the supply chain parameters in the logistics chains, but also by failures in such deliveries due to opportunistic behavior of suppliers, that is, due to low supply discipline. In this context, it is specifically needed to point out the precedents of consumers' appeal to suppliers with requests that go beyond their obligations, outlined in the contracts. This practice generates logistics risks that arise as a result of the limits of suppliers' loyalty to the consumers [24]. Third, in the case of several construction projects at the same time, it is appropriate to justify the rules for their managers' access to limited resources that preclude the emergence of logistics conflicts between them. Fourth, it is necessary to plan deliveries for the needs of the resource support for construction projects, taking into account the rationalization of their logistics system based on lean manufacturing principles. Fifth, it is recommended to develop a contract strategy for the resource support of construction projects that determines the rules for agreeing of supply contracts, logistic coordination of supplies, the placement priorities of supply orders (including the rationale for the methods of such placement) and rapid response to negative logistical precedents (the emergence of a shortage of material resources, threatening to interrupt construction projects, breaking economic ties with suppliers, etc.) [25-27]. Sixth, it is necessary to take into account the influence of individual features of construction projects on the organization of their resource support.

Thus, we correlate the prospects for regulating management of the logistics risks in the resource support of construction projects with an increase in the degree of "measurability" of uncertainty in this type of activity. Achieving this goal involves creation of the integral picture of functioning of logistics in the implementation of construction projects. It should facilitate the detection and analysis of spatial and temporal parameters for performing logistics operations. In addition, it should create objective prerequisites for revealing the logistics vulnerabilities of the latter, but also detect unnecessary operations and processes related to material and technical supply, production and technological equipment and supply chain management, which do not add value to consumers for the construction organizations' services. Improvement of such a regulation should be carried out taking into account the 
following provisions. First, the management of the logistics risks should fit the overall concept of the risk management for construction projects. Within the framework of such coordination, special attention should be paid to the issue of providing the facilities under construction with equipment, since its acquisition, although being a logistics operation, is of an investment nature. Second, the plans for resource support of the construction projects should not be limited solely to the procurement plans. The latter should be targeted, that is, are to be finalized to the plans of the draft contracts of supply, provision of services and works with specific (most likely) performers. The essential contractual terms contained in these projects must be harmonized in order to ensure uniformity and rhythm of supply. The drafts contracts, prior to their legal expertise, must necessarily undergo a logistics expertise. The latter should exclude possible discrepancies between the requirements from various resource support services. Third, purchases for the needs of the construction projects should be balanced taking into account the transaction risks that arise when placing orders for deliveries. Fourth, coordination in the system of resource support for the construction projects should be carried out taking into account the specificity of the functional cycles of logistics and the applicability of alternative modes of intervention into operational logistics activities in course of their implementation. Fifth, it is necessary to develop a system of key indicators of the effectiveness of resource support for the construction projects, normalize their values and conduct logistics controlling. The monitoring of logistics risks should be an integral component of the last functional block. Sixth, construction organizations should constantly make changes in the policy of managing such risks, taking into account the evolution of the international ISO quality standards and the specifics of emergence of risk factors in practice of the industry [28-30]. Seventh, construction organizations should control the process of consistent balancing of the logistics interactions with all stakeholders, since their sustainable development largely depends on that. Eighth, in case of the integrated development of territories for housing construction, special attention should be devoted to placing a network of logistics capacities, which are necessary for the infrastructure (resource) support of the construction projects implemented simultaneously.

\section{References}

1. A. P. Sukhodolov, N. G. Novikova, T. I. Kubasova, G. V. Khomkalov, I. V. Lavygina, All-Russian Criminological Journal, 12(1), 92-100 (2018)

2. T. V. Svetnik, Baikal Research Journal, 8(4), 26 (2017)

3. T. I. Kubasova, N. G. Novikova, A. P. Sukhodolov, Baikal Research Journal, 8(4), 23 (2017)

4. I. V. Tsvigun, S. A. Astafiev, Bulletin of the Irkutsk State Economic Academy (Baikal State University of Economics and Law), 6, 40-42 (2011)

5. I. I. Mazur, V. D. Shapiro, Project management (Higher School, Moscow, 2001)

6. Russian Federal State Statistics Service (http://www.gks.ru, 2018)

7. Rosstat, Russian Statistical Yearbook: 2017 (Rosstat, Moscow, 2017)

8. J. Kornai, Deficit (Nauka Publishing House, Moscow, 1990)

9. Judicial Department at the Supreme Court of the Russian Federation (http://www.cdep.ru, 2018)

10. V. V. Tkach, O. A Vorobyeva, FES: Finance. Economy. Strategy, 4, 5-11 (2017)

11. GOST P 56002-2014: Assessment of experience and business reputation of construction organizations (Moscow, 2014)

12. V. V. Tkach, E. A. Demin, Logistics - the Eurasian bridge: materials of the 10th Intern. 
scientific-practical. conf., 315-319 (2015)

13. V. V. Tkach, O. A. Vorobyeva, FES: Finance. Economy. Strategy, 3, 40-46 (2017)

14. V. V. Tkach, A. N. Klunko, Audit and Financial Analysis, 6, 295-298 (2016)

15. GOST R 52806-2007: Risk management of projects, general provisions (Moscow, 2006)

16. GOST R IEC 61160-2006: Risk management, formal analysis of the project (Moscow, 2006).

17. ISO 31000: 2009: Risk Management, principles and guidelines (Moscow, 2009)

18. GOST R ISO 9004-2010: management to achieve sustainable success of the organization: approach based on quality management (2010)

19. V. V. Tkach, Russian Entrepreneurship, 2(4), 60 - 65, 73 - 76 (2005)

20. V. V. Tkach, Economics and Management (St. Petersburg), 1(75), $73-77$ (2012)

21. V. V. Tkach, Bulletin of the South Ural State University. Series in Economics and Management, 39(215), 106-110 (2010)

22. ISO 28002: Security management systems for supply chain, requirements with guidance for use (Moscow, 2016)

23. V. V. Tkach, Bulletin of the South Ural State University. Series in Economics and Management, 8(225), 173-177 (2011)

24. V. V. Tkach, RISK, 2, 77-80 (2012)

25. V. V. Tkach, Scientific and Technical Bulletin of the St. Petersburg State Polytechnic University, 5(156), 147-151 (2012)

26. V. V. Tkach, Audit and Financial Analysis, 3, 156-160 (2013)

27. V. V. Tkach, Journal of Legal and Economic Research, 3, 142-145 (2017)

28. M. Y. Veselovsky, M. A. Izmailova, A. V. Bogoviz, S. V. Lobova, Y. V. Ragulina, Quality - Access to Success, 19(163), 30-36 (2018)

29. M. Y. Veselovsky, M. A. Izmailova, A. V. Bogoviz, S. V. Lobova, A. N. Alekseev, Quality - Access to Success, 19(162), 60-66 (2018)

30. G. V. Khomkalov, E. I. Kelberg, Baikal Research Journal, 8(3), 7 (2017) 